\title{
Prevalence of asthma and wheeze in the Highlands of Scotland
}

Jane B Austin, George Russell, Margaret G Adam, Dorothy Mackintosh, Sandra Kelsey, David F Peck

\begin{abstract}
To establish the prevalence of asthma and wheeze in 12 year old children in a region with low background pollution levels, a population of children resident in the Highland Region of Scotland was studied by questionnaire supported by objective data.
\end{abstract}

A respiratory questionnaire was distributed to the parents of 1919 children aged from 12-13 years and attending secondary schools in the educational divisions of Lochaber, Ross and Cromarty, and Inverness including Skye in Highland Region to ascertain history of wheeze and parental awareness of a diagnosis of asthma. Peak expiratory flow (PEF) measurements were carried out before and after a standardised exercise test. Ozone levels were noted.

Questionnaires were completed by 1825 parents (95\% of those invited) and 1702 (93\%) of those returning questionnaires took part in the exercise test. The overall prevalence of reported asthma was $14 \%$ and wheeze $25 \%$. Defined as a fall in PEF of more than $15 \%$ with exercise, the overall prevalence of exercise induced bronchospasm was $9 \%$. In Skye the prevalence of reported asthma was $17 \%$, wheeze $28 \%$, and exercise induced bronchospasm $30 \%$. There were no significant differences between areas for reported asthma or wheeze. There was, however, a highly significant difference between areas for exercise induced bronchospasm, most of which was accounted for by the very high incidence in Skye, which is one of the most rural of the areas studied.

The results of this study do not support the hypothesis that asthma is commoner in urban than rural areas, whether we compare the Highlands with the rest of the UK or areas within the Highlands, or whether we examine reported symptoms or exercise induced bronchospasm. The results do not support an association between atmospheric pollution and the prevalence of asthma.

(Arch Dis Child 1994; 71: 211-216)

Asthma is the commonest chronic disorder of childhood with a low mortality but a significant morbidity. ${ }^{1}$ Although a review of prevalence studies since 1984 showed little evidence of an increasing trend that could not be explained by the different methods used in each study, ${ }^{2}$ two recent studies demonstrate an apparent increase in the prevalence of asthma that is not easily explained by changing definitions of asthma or different methodology. The study by Burr et al of 12 year old Welsh children showed an increase in reported asthma from 6\% to $12 \%$ over the 15 years from 1973 to 1988 , which was supported by objective evidence from an exercise test showing an increase in both mild and severe asthma. ${ }^{3}$ The prevalence of wheeze also rose from $17 \%$ to $22 \%$. A recent survey of Aberdeen schoolchildren using the same questions but a different method of application as a study 25 years previously, ${ }^{4}$ showed an increase of reported asthma from $4 \cdot 1 \%$ to $10 \cdot 2 \%$ between 1964 and 1989 , with a similar increase for wheeze.

The reasons for the increasing prevalence of wheeze and asthma are unclear but environmental factors such as air pollutants including ozone have been implicated. The Swedish study by Andrae et al suggests that pollutants may act synergistically to increase bronchial hyper-reactivity and allergy in children. ${ }^{5} \mathrm{~A}$ review of the literature by Abramson and Voigt concluded that respiratory symptoms are associated with ozone and other pollutants but also suggested the need for further research. ${ }^{6} \mathrm{~A}$ study of a remote and relatively unpopulated and unpolluted area within the UK would therefore be of interest.

The Highland Region of Scotland is free from heavy industry and there is evidence to suggest low pollution levels. The busiest road in the Highland Region is in Inverness, with a traffic flow of 23000 vehicles per day whereas the M25 London ring road, for example, has in excess of 120000 vehicles per day (information courtesy of Highland Regional Council). Ozone levels in the Highlands are recorded at the Strath Vaich site. In 1989/90 levels were the lowest in the UK with only 28 exceedences beyond 60 parts per billion (ppb) hourly mean ozone concentration. This can be compared with the recordings at Lullington Heath, a rural site in south east England with 400 hours when ozone exceed 60 ppb. ${ }^{78}$

A study carried out by Inverness District Council between July 1992 and June 1993 showed that nitrogen dioxide levels in Inverness were within the EC air quality 'limit' value (information courtesy of Inverness District Council).

At $25304 \mathrm{~km}^{2}$, the Highland Region is the largest region in Scotland, covering one third of the country. In contrast the total population of 204200 accounts for only $4 \%$ of Scotland's inhabitants. The population density in the 
Highland Region is therefore only eight persons per $\mathrm{km}^{2}$, which is low compared, for instance, with Lothian in south east Scotland which has a population density of 427 persons per $\mathrm{km}^{2}$ (figures courtesy of Highland Regional Council and provisional census 1991, General Register Office, Edinburgh). Within the Highland Region there is considerable variation in population density, from the small city of Inverness with a population of 42914 to the scattered crofting communities on the island of Skye.

The present study therefore examines the prevalence of asthma and wheeze in 12 year olds in a unique region with low pollution.

\section{Subjects and methods}

The population sample for the study comprised children in their first year at secondary school with a date of birth between 1.3.79 and 29.2.80 attending schools in the educational divisions of Lochaber, Ross and Cromarty, Inverness-shire, and Skye. Of the 27 secondary schools in the area, 23 were included in the study; two private schools and two schools for children with profound learning difficulties were excluded, each having four or fewer children in the age group being studied. For practical reasons, 48 children with dates of birth within the study range but attending primary schools were not included.

Children were selected by deciding statistically the minimum number of children to be seen according to school size, using the sampling procedure guidelines of the British Association for the Study of Community Dentistry. ${ }^{9}$ Pupil rolls for the first years in the schools studied ranged from seven to 204, according to class register at the time of the study. For small schools (pupil roll in first year $<100$; 12 schools) all pupils were invited; for medium sized schools (pupil roll 100 to 150 ; five schools) one in two pupils were selected from the class register; for larger schools (pupil roll $>150 ; 6$ schools) one in three pupils were selected from the class register. The pupils were selected randomly and without prior knowledge of their medical status. Where possible more than the calculated minimum number of children took part in the study.

The questionnaire and exercise test for this study have been used previously in several studies by Burr et $a l^{3} 10$ but additional questions regarding birth place, and period of residence were included. In March/April 1992 questionnaires were distributed by the schools

Table 1 Symptoms reported on questionnaire; figures are number (\%)

\begin{tabular}{lcllll}
\hline & $\begin{array}{l}\text { Reported } \\
\text { asthma } \\
(n=236)\end{array}$ & $\begin{array}{l}\text { No reported } \\
\text { asthma } \\
(n=1466)\end{array}$ & $\begin{array}{l}\text { Boys } \\
(n=888)\end{array}$ & $\begin{array}{l}\text { Girls } \\
(n=814)\end{array}$ & $\begin{array}{l}\text { Total } \\
(n=1702)\end{array}$ \\
\hline Wheeze ever & $234(99)$ & $189(13)$ & $232(26)$ & $191(23)$ & $423(25)$ \\
Wheeze in last 12 months & $205(87)$ & $123(8)$ & $186(21)$ & $142(18)$ & $328(19)$ \\
Wheeze with cold & $209(89)$ & $147(10)$ & $197(22)$ & $159(20)$ & $356(21)$ \\
Wheeze without cold & $211(89)$ & $113(8)$ & $185(21)$ & $139(17)$ & $324(19)$ \\
Wheeze with running & $196(83)$ & $116(8)$ & $171(19)$ & $141(17)$ & $312(18)$ \\
Wheeze with animals & $77(33)$ & $20(1)$ & $51(6)$ & $46(6)$ & $97(6)$ \\
Wheeze with food, worry, & $119(50)$ & $43(3)$ & $99(11)$ & $63(8)$ & $162(10)$ \\
$\begin{array}{l}\text { excitement, other reasons } \\
\text { Breathless wheeze }\end{array}$ & $208(88)$ & $73(5)$ & $167(19)$ & $114(14)$ & $281(17)$ \\
Nocturnal wheeze & $181(77)$ & $68(5)$ & $145(16)$ & $104(13)$ & $249(15)$ \\
\hline
\end{tabular}

to the parents of the children selected to take part. Second questionnaires were sent to non-responders and, where possible, the reasons for not replying were established. 'Reported asthma' was based on the response to the question 'Has your child ever suffered from any of the following? ... asthma.' Wheeze was defined by a positive response to the question 'Has a wheeze - that is, a whistling noise (high or low pitched) ever been heard coming from your child's chest?'

Exercise testing was performed using the protocol described by Burr et al (and personal communication). ${ }^{3} 10$ Exercise induced bronchospasm was defined as a fall in peak expiratory flow (PEF) with exercise of greater than $15 \%$. Exercise testing was carried out between April and June 1992 by four teams of observers who had taken part in a training day to ensure that techniques were standardised according to the protocol. Children were seen in groups of 10-15 in an indoor hall at school between 9 am and $4 \mathrm{pm}$. Questionnaires were checked for completeness and inconsistencies. A note was made of treatment that had been taken on the test day. Where possible the procedure had been explained in advance to allay any anxiety regarding the nature of the exercise test; in the more remote areas an explanation was given on the test day.

Height was measured after the children had removed their footwear. Tanner's standard measurement technique was used with a Microtoise measuring instrument (Child Growth Foundation). Each child was given a numbered label that corresponded to the peak flow meter used, to ensure that the same instrument was used before and after exercise by the same child and the same observer. PEF before exercise was measured five times for each pupil using a mini-Wright peak flow meter (Clement-Clarke). Any pupil whose PEF was less than $70 \%$ of the predicted value for height was excluded from running in order to avoid exercising a child with bronchoconstriction at rest. The subjects then ran, under supervision, as fast as possible, for exactly six minutes, having ensured that no exercise was taken before testing.

To ensure that the exercise represented a workload sufficient to result in bronchoconstriction, that is, sufficient to induce a tachycardia of 170 or more, the heart rate was measured by palpation of the radial pulse within two minutes of completing the exercise. As bronchoconstriction has been shown to reach a peak five minutes after exercise, ${ }^{11}$ each pupil rested for five minutes after exercise before repeating five PEF measurements. The mean of the three highest readings was calculated separately for exercise before and after PEF. ${ }^{12}$

Instrument variability was examined by 10 healthy adult females performing PEF measurements on all the meters both before and after the study.

Dry and wet bulb temperatures were recorded using a whirling hygrometer (Astell London Ltd) for each group of children while they were exercising. The time of the exercise 
Table 2 Reported asthma, residence, and place of birth; figures are number (\%)

\begin{tabular}{lcc}
\hline & $\begin{array}{c}\text { Subjects in study } \\
(n=1702)\end{array}$ & $\begin{array}{c}\text { Reported asthma } \\
(n=236)\end{array}$ \\
\hline $\begin{array}{l}\text { Where born } \\
\text { Highland Region }\end{array}$ & $1238(73)$ & $175(74)$ \\
$\begin{array}{l}\text { Scotland outside } \\
\text { Highland Region }\end{array}$ & $306(18)$ & $40(17)$ \\
$\begin{array}{l}\text { Elsewhere } \\
158(9)\end{array}$ & $21(9)$ \\
Lived in Highland Region (years) & $190(81)$ \\
$>10$ & $1339(79)$ & $19(8)$ \\
$5-10$ & $177(10)$ & $197(11)$ \\
$<5$ & $186(11)$ & $27(10)$ \\
\hline
\end{tabular}

test was noted, and Strath Vaich ozone data for the study period were obtained from Warren Spring Laboratory, Stevenage.

To test for bias in the selection of or participation by subjects for the study, the medical records of the children invited to participate were compared with those of the children not invited. The diagnosis of asthma for this purpose was based on the school medical records which included a questionnaire completed routinely by parents before the pupils' entry to secondary school, that is, less than one year before the study.

Data were entered into a computer database, validated and cross checked to reduce errors, and inconsistencies were checked with subjects and parents. Statistical packages used were Mini-tab and programs written by Professor David Kerridge.

Before starting the study, ethical approval was obtained from the ethics committee of the Highland Health Board.

\section{Results}

STUDY POPULATION

The area studied covered $17663 \mathrm{~km}^{2}$ with a total population of 164320 , comprising $80 \%$ of the Highland Region's population (provisional census data, General Register Office, Edinburgh 1991).

A total of 1919 children were invited to participate. In 19 of the schools all the children were invited to participate. In the remaining four schools the children were selected as described, for practical reasons. Altogether 1825 (95\% of those invited) returned questionnaires and 1702 (93\% of those returning questionnaires) took part in the exercise test.

Of the secondary school pupils who were not invited to participate ( 165 boys and 161 girls), subsequent examination of the medical records showed that in $24(7 \%)$ the parents were aware of the diagnosis of asthma. Of the children who participated, the parents of $9 \%$ were aware of the diagnosis of asthma, according to the school medical records. The school medical records of the 94 pupils (5\% of the total invited; 51 boys and 43 girls) who declined to participate in both the survey and exercise test were also examined and showed that six $(6 \%)$ were asthmatic. Reasons for not taking part included leukaemia, social factors, and confidentiality.

QUESTIONNAIRE DIAGNOSIS, SYMPTOMS, AND TREATMENT

From table 1 it can be seen that $25 \%$ of subjects had wheezed during their lifetime. Nineteen per cent of the pupils had wheezed within the last year with the commonest triggers for wheeze being colds and exercise.

Of those taking part in the exercise test, asthma was reported on the questionnaires of $146(16 \%)$ boys and $90(11 \%)$ girls. Inhalers were used by $265(16 \%)$ of those exercising.

\section{RESIDENCE IN THE HIGHLANDS AND AREA OF} BIR'TH

The number of years that the children have resided in the Highlands is shown in table 2 with $73 \%$ of children being native to the Highlands and accounting for $74 \%$ of the asthmatics.

\section{EXERCISE TEST - POPULATION STUDIED}

Altogether 123 subjects completed the questionnaire but did not participate in the exercise test: 20 because of physical conditions (congenital heart disease, fractures), one with a respiratory condition (nasal problems), 70 because of absence on the test day, and 32 who refused exercise because of peer pressure, overweight, or social reasons.

A total of 1702 performed a PEF measurement before exercise and 1640 after exercise. Of the 62 not performing PEF measurements after exercise, 13 had an initial PEF $<70 \%$ and were not exercised, 41 were unable to run six minutes, seven were too dizzy or wheezy after exercise to perform a measurement, and one sustained an eye injury on the way to the gym. In all 1688 ran and 1647 completed the six minutes of exercise.

The mean (SD) height of the subjects was 153 (8) $\mathrm{cm}$ for boys and 155 (7) cm for girls. Mean heart rate after exercise was 154 (19) beats/min. There was no appreciable difference in heart rate after exercise between boys or girls, nor between asthmatics and nonasthmatics. The mean heart rate after exercise for Skye children was the lowest of all the schools with a mean of 130 (10) beats $/ \mathrm{min}$ (range 98-148).

Table 3 Results of exercise test; figures are number (\%)

\begin{tabular}{|c|c|c|c|c|c|c|}
\hline & $\begin{array}{l}\text { Current wheeze } \\
\text { (within last } \\
12 \text { months) } \\
(n=328)\end{array}$ & $\begin{array}{l}\text { Reported } \\
\text { asthma } \\
(n=236)\end{array}$ & $\begin{array}{l}\text { No } \\
\text { reported } \\
\text { asthma } \\
(n=1466)\end{array}$ & $\begin{array}{l}\text { Boys } \\
(n=888)\end{array}$ & $\begin{array}{l}\text { Girls } \\
(n=814)\end{array}$ & $\begin{array}{l}\text { Total } \\
\text { taking part } \\
\text { in exercise } \\
(n=1702)\end{array}$ \\
\hline $\begin{array}{l}\text { PEF }<70 \% \text { before exercise and not exercised } \\
\text { Unable to run } 6 \text { minutes } \\
\text { Too dizzy or wheezy to perform PEF after exercise } \\
\text { Fall in PEF }>15 \% \text { with exercise }\end{array}$ & $\begin{array}{c}2(1) \\
22(7) \\
5(2) \\
80(24)\end{array}$ & $\begin{aligned} & (1) \\
20 & (9) \\
4 & (2) \\
62 & (26)\end{aligned}$ & $\begin{array}{l}10(1) \\
21(1) \\
3(0) \\
89(6)\end{array}$ & $\begin{array}{r}9(1) \\
12(1) \\
2(0) \\
80(9)\end{array}$ & $\begin{array}{r}4(1) \\
29(4) \\
5(1) \\
71(9)\end{array}$ & $\begin{array}{r}13(1) \\
41(2) \\
7(0) \\
151(9)\end{array}$ \\
\hline
\end{tabular}


Table 4 Geographical variation in observed prevalence; figures are number (\%)*

\begin{tabular}{lllcrrr}
\hline & $\begin{array}{l}\text { Largest town or } \\
\text { village } \\
\text { (total population) }\end{array}$ & $\begin{array}{l}\text { Reported } \\
\text { asthma }\end{array}$ & $\begin{array}{l}\text { Wheeze } \\
\text { ever }\end{array}$ & $\begin{array}{l}\text { Fall in PEF } \\
\text { >15\% with } \\
\text { exercise }\end{array}$ & $\begin{array}{l}\text { Unable to } \\
\text { complete PEF } \\
\text { after exercise }\end{array}$ & $\begin{array}{l}\text { Total } \\
\text { taking part in } \\
\text { exercise test }\end{array}$ \\
\hline Inverness & Inverness (42 914) & $70(15)$ & $110(23)$ & $33(7)$ & $12(2)$ & 4 \\
Lochaber & Fort William (10 774) & $22(10)$ & $54(24)$ & $24(10)$ & $11(5)$ & 229 \\
Nairn, Strathspey, Fort & Nairn (8316) & $44(14)$ & $76(24)$ & $21(7)$ & $6(2)$ & 322 \\
$\quad \begin{array}{l}\text { Augustus, Black Isle } \\
\text { Easter Ross }\end{array}$ & Alness (5907) & $69(15)$ & $131(28)$ & $36(8)$ & $20(4)$ & 474 \\
Weste & Portree (2561) & $18(17)$ & $30(29)$ & $32(30)$ & $9(9)$ & 105 \\
Total & Ullapool (1541) & $13(14)$ & $22(24)$ & $5(5)$ & $4(4)$ & 91 \\
\hline
\end{tabular}

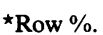

\section{EXERCISE TEST - RESULTS}

The results of the exercise test provided objective evidence to support the questionnaire findings. PEF results before and after exercise were compared, and the difference expressed as a percentage of the result before exercise. Results in relation to diagnosis are illustrated in table 3.

Of the 62 asthmatics with a greater than $15 \%$ fall in PEF with exercise, 21 had used an inhaler within eight hours of exercise. There was no significant correlation between percentage change in PEF and ambient temperature $(r=0.07)$, relative humidity $(r=-0.05)$, or heart rate $(r=0.03)$.

\section{GEOGRAPHICAL RESULTS}

These are shown in table 4. The division into areas was based on areas noted before the study to have specific health needs or social deprivation. These areas are not synonymous with the educational divisions described in the method for defining the study area. Skye showed the highest prevalence within the Highlands for both reported asthma and exercised induced bronchoconstriction.

\section{MACHINE VARIABILITY}

The design of the study made it necessary to use 58 peak flow meters but these were checked against each other and intermachine variation was found to be negligible. In contrast, the SD in PEF before exercise for all the subjects was 60 : for boys 61 and girls 58 . However, as the study was based on comparisons of PEF before and after exercise rather than on absolute PEF values, the effects of intermachine variability would in any case be slight.

\section{ENVIRONMENT}

Within each school the asthmatics and non-asthmatics exercised under the same conditions.

Table 5 Comparison of Highland Region with Wales and Aberdeen (\%)

\begin{tabular}{llll}
\hline & $\begin{array}{l}\text { Reported } \\
\text { asthma }\end{array}$ & $\begin{array}{l}\text { Wheeze during } \\
\text { lifetime }\end{array}$ & $\begin{array}{l}\text { Fall in } P E F>15 \% \\
\text { with exercise }\end{array}$ \\
\hline New Zealand & 17 & 27 & $12 \cdot 2$ \\
Highlands of Scotland & 14 & 25 & 9 \\
Wales & 12 & $22 \cdot 3$ & $7 \cdot 7$ \\
Aberdeen & $10 \cdot 2$ & $19 \cdot 8^{\star}$ & Not applicable, survey only \\
\hline
\end{tabular}

$\star$ Wheeze in last three years.
Mean dry bulb temperature recorded during exercise was $19^{\circ} \mathrm{C}$ (range 13-28); mean relative humidity was 63 (range 36-89). One of the lowest mean temperatures was recorded on Skye with a value of $15^{\circ} \mathrm{C}$ (range 13-16) and a mean relative humidity of 71 (range 62-80).

Mean (SD) hourly ozone was 40 (11) ppb with a maximum of $76 \mathrm{ppb}$ (provisional ozone data from Warren Spring Laboratory, Strath Vaich site). The World Health Organisation guidelines of 76-100 ppb for hourly concentration were not exceeded during the period April 1992 to June 1992.

\section{Discussion}

METHODOLOGY - PATIENT SELECTION

The identification of subjects for this study was based on well recognised selection procedures ${ }^{9}$ and there is no reason to believe that there was any systematic selection bias. Examination of the school medical records of children invited to complete questionnaires, children not invited, and children who completed questionnaires but did not undertake an exercise test, showed no significant difference between the three groups in the prevalence of asthma as reported by the parents.

\section{METHODOLOGY - QUESTIONNAIRE}

As there is no satisfactory definition or specific diagnostic test for asthma, questions were included regarding symptomatology and treatment. Parental reporting of asthma was, however, included and it is interesting to note the discrepancy between parental knowledge of a diagnosis of asthma and the symptom of wheeze.

Questionnaires result in errors due to poor recall or variable interpretation of questions. It has been suggested, however, that recent wheeze, diagnosed asthma, and exercise wheeze are useful questions for epidemiological purposes as opposed to questions regarding night cough that are probably of little value in prevalence studies. ${ }^{13}$

\section{METHODOLOGY - EXERCISE TEST}

The method used for exercise testing is important. Free running as used in this study has been shown to be a reliable method for assessing bronchial hyper-responsiveness, with normal subjects having an upper limit of $14 \%$ for fall in PEF with exercise. ${ }^{311}$ In 
contrast, Ninan and Russell found that a cold air enhanced exercise test using a bicycle ergometer was an unsatisfactory tool for epidemiological surveys, possibly because they exercised their children until they attained a predetermined change in heart rate, rather than seeking to achieve the maximum exercise tolerated. ${ }^{14}$ The humidity of the inspired air is also a factor; Hahn et al suggest that airways response depends on the degree of water loss rather than on the cooling of the airways. ${ }^{15}$

PEF measurements made with the miniWright peak flow meter used in this study correlate well $(r=0.995)$ with those made using the standard instrument, ${ }^{16}$ as used in the Welsh study by Burr. ${ }^{3} 10$

Numerous studies have demonstrated both over and under estimation of PEF with various instruments. ${ }^{17}$ In this study each child acted as his own control, with the same instrument being used by the same child, and the result documented by the same observer before and after exercise. The variation of PEF within each subject was very much greater than variation between instruments. The SD for $\mathrm{PEF}$ in this study was in line with the figure of 60 that is quoted in standard respiratory tables. ${ }^{18}$ The figures for SD in PEF quoted by Cotes et al are 78.4 for boys and 70.6 for girls, ${ }^{19}$ which suggest that the within subject variation in our study was not excessive.

The questionnaire identified a greater number of asthmatics than the exercise test; this is to be expected as asthmatics may not demonstrate bronchial hyper-responsiveness on the particular test day because of the inherent variability of asthma, and the control afforded by treatment. The converse is also true, with some asymptomatic subjects showing a significant fall in PEF with exercise. ${ }^{20}$ Moreover, it may be worthwhile detecting milder or even asymptomatic asthmatics; mortality does not always correlate with the severity of the symptoms and death can occur even in those subjects with mild symptoms. $^{21}$ Exercise test results must therefore be interpreted with caution, but a positive result in association with clinical symptoms strongly suggests a diagnosis of asthma.

PREVALENCE OF EXERCISE INDUCED

BRONCHOCONSTRICTION

This study may underestimate exercise induced bronchoconstriction as the mean heart rate was less than that recommended (170 beats $/ \mathrm{min}$ ) for inducing maximum bronchoconstriction, $^{22}$ although we were unable to demonstrate any correlation between the change in PEF and the heart rate after exercise.

\section{GENDER DIFFERENCES}

Although more boys than girls are asthmatic there is little gender difference for bronchial hyper-reactivity, ${ }^{23}$ and this study supports these observations.
COMPARISON WITH OTHER REGIONS

It is not possible to compare different studies in detail as different methodology is used. Exactly the same protocol, however, was used in the Highlands as in Cardiff ${ }^{3}$ and New Zealand, ${ }^{24}$ thereby allowing some comment on the figures presented in table 5 .

Several studies have shown a higher prevalence of asthma in urban areas compared with rural areas in non-industrialised countries. ${ }^{25-27}$ Higher prevalence figures in western society suggest that asthma is a disease of civilisation.

In the UK, the Highland Region of Scotland, a predominantly rural area, has a higher prevalence rate for asthma and wheeze than more urban areas such as Aberdeen and Cardiff (raw data not available for statistical analysis), suggesting that in this country the prevalence is not necessarily higher in urban than in rural areas.

Evidence from New Zealand also supports this view. New Zealand is similar to the Highlands of Scotland in terms of a mountainous terrain and a mainly agricultural economy, although the population density is different ${ }^{28}$ (New Zealand population density 58 per $\mathrm{km}^{2}$, Highlands six per $\mathrm{km}^{2}$ ). Using the same protocol and involving one of the authors of the Welsh study, the results from New Zealand showed a higher prevalence of asthma than the Highlands (table 4). The differences between countries are greater for asthma than for wheeze suggesting that differing diagnostic criteria may account for some of the differences between studies.

DIFFERENCES WITHIN THE HIGHLAND REGION There was no difference in the prevalence of reported asthma between the natives of the Highlands and the incomers to the Highland Region, suggesting that in this age group environmental factors are more important than genetic factors in the aetiology of the condition. This view is supported by Strachan et al who showed that until the age of 11 regional differentials for asthma and wheeze were related to region of current residence rather than region of birth, and that the difference between migrants and non-migrants was negligible. ${ }^{29}$

The prevalence of asthma and wheeze in some schools is higher or lower than that in the total population studied. The interpretation of this finding is difficult in view of the small numbers involved, with the exception of Skye where the study group numbered 105 and the prevalence of exercised induced bronchospasm was much higher than in the general population; the significant $(p<0.001)$ difference between areas in the prevalence of exercise induced bronchospasm was almost entirely due to this excess. In general the results within the Highland Region suggest that relatively urban areas such as Inverness (definition based on population size) do not have a higher prevalence of asthma or wheeze than rural areas (table 5).

These differences in asthma prevalence between the Highland Region and other parts 
of the world, and between different areas within the Highland Region, are likely to reflect environmental differences on which we can only speculate. Possible factors include allergens, although the triggers identified by our subjects (table 1) do not differ significantly from those identified in studies elsewhere. ${ }^{324}$ Climatic differences, ${ }^{30} 31$ such as rainfall, have been implicated in asthmatic attacks. The rainfall figures for the study period show that rainfall in the west of the Highland Region (for example, Lochcarron, Wester Ross $163 \mathrm{~mm}$ rainfall during April 1992) was higher than that on the east of the Highland Region (for example, Inverness $37 \mathrm{~mm}$ April 1992) however, we have insufficient information to comment further. Social factors might also be important. In general, the family income in the Highland Region is low and may well affect disease prevalence through differences in housing and lifestyle. It is fashionable to ascribe the recent increase in the prevalence of asthma to atmospheric pollutants, such as nitrogen oxides, which have been implicated in the high prevalence of respiratory symptoms and asthma in western society. Pollution can undoubtedly trigger asthmatic attacks and affect lung function but the evidence regarding the role of pollutants in the development of asthma is much less certain. ${ }^{5632}$ Low pollution levels suggested by traffic volumes, nitrogen dioxide levels in Inverness, and ozone data suggest that pollution is unlikely to be a major factor in explaining the prevalence of asthma and wheeze in the Highlands of Scotland. A recent German study also supports this view, as no significant difference was shown in the lifetime prevalence of wheeze in two areas differing in pollution levels, despite the possible difficulties in diagnostic labelling for asthma and bronchitis. ${ }^{33}$

In order to explain the reasons for the high prevalence of asthma and wheeze in the Highland Region, and the high prevalence of exercise induced bronchospasm in Skye, further study is required. It is, however, unlikely that pollution is a major factor in the aetiology of asthma in this population.

We wish to thank Dr Mike Burr for his protocol and helptul advice, and Professor D Kerridge and Mrs Irene Angus for making computing facilities and programmes available during the writing of the paper. We are grateful to school nurses $G$ al Bryce, Morag Campbell, Jane Swain, and Isobel Stewart for data collection. We wish to thank Dr D H Franklin, ches physician for his support; medical audit and department of information services, Highland Health Board for assistance and all the school nurses, schools, PE teachers, pupils, parents and secretaries for contributing so enthusiastically.

We ares for contributing so enthusiastically. We are grateful to Allan and Hanburys for providing peak fow meters and mouthpieces and

1 Speight ANP, Lee DA, Hey EN. Underdiagnosis and undertreatment of asthma in childhood. $B M F 1983 ; 286$ : 1253-6.

2 Anderson HR. Is the prevalence of asthma changing? Arch Dis Child 1989; 64: 172-5.
3 Burr ML, Butland BK, King S, Vaughan-Williams E. Changes in asthma prevalence: two surveys 15 years apart. Arch Dis Child 1989; 64: 1452-6.

4 Ninan TK, Russell G. Respiratory symptoms and atopy in Aberdeen schoolchildren: evidence from two surveys 25 vears apart. BMF 1992; 304: 873-5.

5 Andrae S, Axelson O, Björkstén B, Fredriksson $M$, Kjellman N-IM. Symptoms of bronchial hyperreactivity and asthma in relation to environmental factors. Arch Dis Child 1988; 63: 473-8.

6 Abramson M, Voigt T. Ambient air pollution and respiratory disease. Med F Aust 1991; 154: 543-51

7 Warren Spring Laboratory. Air quality in the UK: a summar of results from instrumented air monitoring networks. Warren Spring Laboratory report 1990/91, report no LR 883. Stevenage: Warren Spring Laboratory, 1990/91.

8 Report of the Advisory Group on the Medical Aspects of Air Pollution Episodes. Ozone. (First report.) London HMSO, 1991

9 Palmer JD, Anderson RJ, Downer MC. Guidelines for prevalence studies of dental caries. Community Dent Health 1984; 1: 55-66.

10 Burr ML, Eldridge BA, Borysiewicz LK. Peak expiratory flow rates before and after exercise in schoolchildren. Arch Dis Child 1974; 49: $923 \%$

11 Anderson SD, Silverman M, König P, Godfrey S. Exercise induced asthma. British foumal of Diseases of the Chest 1975; 69: 1-39.

12 Oldham PD, Cole TJ. Estimation of the $\mathrm{FEV}_{1}$. Thorax 1983; 38: $662-7$

13 Peat JK, Salome CM, Brett GI, Bauman A, Woolcock AJ Reliability of a respiratory history questionnaire and effect of mode of adninistration on classification of asthma in of mode of adninistration on -7.

14 Ninan TK, Russell G. Is exercise testing useful in community based asthma survey? Thorax 1993; 48 $1218-21$

15 Hahn A, Anderson SD, Morton AR, Black JL, Fitch KD. A reinterpretation of the effect of temperature and water content of the inspired air in exercise-induced asthma. $A m$ Rei Respir Dis 1984; 130: 5759

16 Wright BM. A miniature Wright peak-flow meter. BMF 1978; ii: $1627-8$.

17 Miller MR, Dickinson SA, Hitchings DJ. The accuracy of portable peak flow meters. Thorax 1992; 47: 904 -9.

18 Cotes JE. Lung function assessment and applicution in medicine. 5th Ed. Oxford: Blackwell, 1993

19 Cotes JE, Dabbs JM, Hall AM, Axford AT, Laurence KM Lung volumes, ventilatory capacity and transfer factor in healthy British boy and girl twins. Thorax 1973; 28: $709-1 \overline{3}$

20 Phelan PD. Hyperresponsiveness - a determinant of the outcome in childhood asthma. Am Rev Respir Dis 1991; 143: $1463-7$

21 Roberston CF, Rubinfeld AR, Bowes (i. Paediatric asthma deaths in Victoria: the mild are at risk. Pediatr Pulmonol 1992; 13: $95-100$

22 Tsanakas JN, Bannister OM, Boon AW, Milner RDG. The 'Sport-tester': a device for monitoring the free running test. Arith Dis Child 1986; 61:912-4.

23 Stempel DA, Szefler SJ. Asthma. Pediutr Clin North Am 1992; 39: 1185-204.

24 Barry DMJ, Burr ML, Limb ES. Prevalence of asthm among 12 year old children in New Zealand and South Wales: a comparative survey. Thorax 1991; 46: 405-9.

25 Keeley DJ, Neill P, Gallivan S. Comparison of the prevalence of reversible airways obstruction in rural and urban Zimbabwean children. Thorax 1991; 46: 549-53.

26 Van Niekerk CH, Weinberg EG, Shore SC. Heese HdeV, Van Schalkuyk DJ. Prevalence of asthma: a comparative study of urban and rural Xhosa children. Clinical Allergv 1979; 9: 319--24.

27 Terblanche E, Stewart RI. The prevalence of exercise induced broncho-constriction in Cape Town schoolchildren. S Afr Med f 1990; 78: 744-7.

28 Whitaker's almunac. 125th Ed. London: J Whitaker, 1993.

29 Strachan DP, Golding J, Anderson HR. Regional variation in wheczing illness in British children: effect of migration during carly childhood. I Epidemiol Community Health $1990 ; 44: 231-6$

30 Klabuschnigg A, Götz $\mathrm{M}$, Horak $\mathrm{F}$, et al. Influence of aerobiology and weather on symptoms in children with aerobiology and weather on symptom

31 Rossi OVJ, Kinnula VL, Tienari J, Huhti E. Association of severe asthma attacks with weather, pollen, and air pollutants. Thorux 1993; 48: 244-8.

32 Schmitzberger R, Rhomberg K, Büchele H, et al. Effects of air pollution on the respiratory tract of children. Pediatr Pulmonol 1993; 15: 68-74.

33 Mutius von E, Fritzsch C, Weiland SK, Röll G, Magnussen $\mathrm{H}$. Prevalence of asthma and allergic disorders among children in united Germany: a descriptive comparison. BMF 1992; 305: 1395-9. 